\title{
Confirming the Composition of Shape Memory Alloys by Microstructural Characterization
}

\author{
D.F. Susan ${ }^{1}$, T.E. Buchheit ${ }^{1}$, J.M. Massad ${ }^{1}$, J. McElhanon ${ }^{1}$, M. Reece ${ }^{1}$, A. Garg ${ }^{2,3}$, and R.D. Noebe ${ }^{2}$ \\ ${ }^{1}$ Sandia National Laboratories, Albuquerque, New Mexico \\ ${ }^{2}$ NASA Glenn Research Center, Cleveland, Ohio \\ ${ }^{3}$ Univeristy of Toledo, Toledo, Ohio
}

It is well known that the properties of shape memory alloys, such as binary Ni-Ti (nitinol), are very sensitive to composition.[1-3] Especially on the Ni-rich side of stoichiometry, the martensite/austenite phase transformation temperature decreases abruptly when Ni is increased only a few tenths of a weight percent.[4] In ternary high temperature shape memory alloys (HTSMAs) containing Pt, Pd, or Hf, this compositional sensitivity can cause even greater shifts in transformation temperature, potentially hundreds of degrees C.[2,3] Figure 1 shows the Austenite-start temperatures of several heats of Ni-Ti-Pt alloys, measured by differential scanning calorimetry (DSC), as a function of aim Pt concentration. Some samples exhibit comparatively low $\mathrm{A}_{\mathrm{s}}$ temperatures. The target composition for all specimens was slightly Ti-rich (50.5 at. \% Ti). However, slight changes in the melt composition due to Ti oxidation, inhomogeneity, or other effects can sometimes push the alloys to the $(\mathrm{Ni}, \mathrm{Pt})$-rich side of stoichiometry. While DSC provides a good measure of phase transformation temperature, it is only indirect evidence of the compositional effect. In addition, the small discrepancies in matrix composition that lead to property changes are often masked within the experimental error of bulk chemical analysis methods. To definitively confirm the (Ni,Pt,Pd)-rich or (Ti,Hf)rich character of a specific lot of material, microstructural characterization is necessary.

Figure 2 displays SEM backscatter photomicrographs and EDS maps from two Ni-Ti-Pt alloys with nominal 16.5 at. $\% \mathrm{Pt}$ and target 50.5 at.\% Ti. One sample exhibited $\mathrm{Ti}_{2}(\mathrm{Ni}, \mathrm{Pt}) / \mathrm{Ti}_{4}(\mathrm{Ni}, \mathrm{Pt})_{2} \mathrm{O}_{\mathrm{x}}$ micron sized particles (Fig. 2a), formed during solidification, supporting evidence of the intended Ti-rich composition. The other specimen contained micron sized (Ni,Pt)-rich precipitates, likely Ti2(Ni,Pt)3, Fig. 2b. The (Ni,Pt)-rich composition of this sample was verified by TEM characterization as well. Figure 3 shows a high density of nm-size (Ni,Pt)-rich monoclinic P-phase $\left(\mathrm{Ni}_{9} \mathrm{Pt}_{4} \mathrm{Ti}_{11}\right)$ as described in detail in an earlier paper.[5] Precipitation of the fine Ni-rich phase confirms that the alloy, which was originally aimed to be a Ti-rich alloy, turned out to be (Ni,Pt)-rich. Precipitation of a fine Ni-rich phase and similar microstructure were observed in a Ni-rich NiTiPd alloy also.[6] The effects of slight changes in composition on phase transformation temperature have been shown by Shimizu et al. [2] for NiTiPd alloys and by Abu Judom et al. [3] for NiTiHf HTSMAs. The present work illustrates a similar effect for NiTiPt HTSMAs. Further careful characterization will be required to quantify the trend of decreasing transformation temperature with compositional changes on the (Ni,Pt)-rich side of stoichiometry in Ni-Ti-Pt alloys.

Sandia National Laboratories is a multi-program laboratory managed and operated by Sandia Corporation, a wholly owned subsidiary of Lockheed Martin Corporation, for the U.S. Department of Energy’s National Nuclear Security Administration under contract DE-AC04-94AL85000.

[1] J. Ma, I. Karaman, and R.D. Noebe, Intl. Mat. Rev., 55 (2010), pp. 257-315.

[2] S. Shimizu, Y. Xu, E. Okunishi, S. Tanaka, K. Otsuka, and K. Mitose,Mater. Lett., 34, (1998), p. 23.

[3] D. Abu Judom, P. Thoma, M. Kao, and D. Angst, US Patent No. 5114504, (1992).

[4] W. Tang, Met. Mat. Trans A, 28A, (1997), pp. 537-544. 
[5] L. Kovarik et al., Acta Mat., 58, 2010, pp 4660-4673.

[6] T.T. Sasaki et al., Met. Mat. Trans. A, 44A, (2013), pp. 1388-1400.

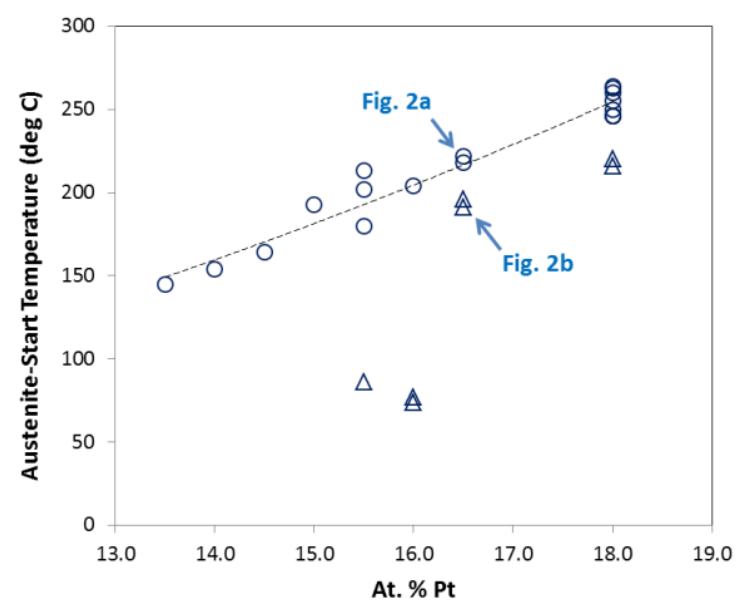

Fig. 1. Plot of Austenite-start temperature, $\mathrm{A}_{\mathrm{s}}$, as a function of aim Pt concentration for several heats of ternary NiTiPt HTSMAs with 50.5 at.\% Ti target composition. Triangles indicate the likely $(\mathrm{Ni}, \mathrm{Pt})$-rich heats. The curve is a fit through the Ti-rich alloys only.
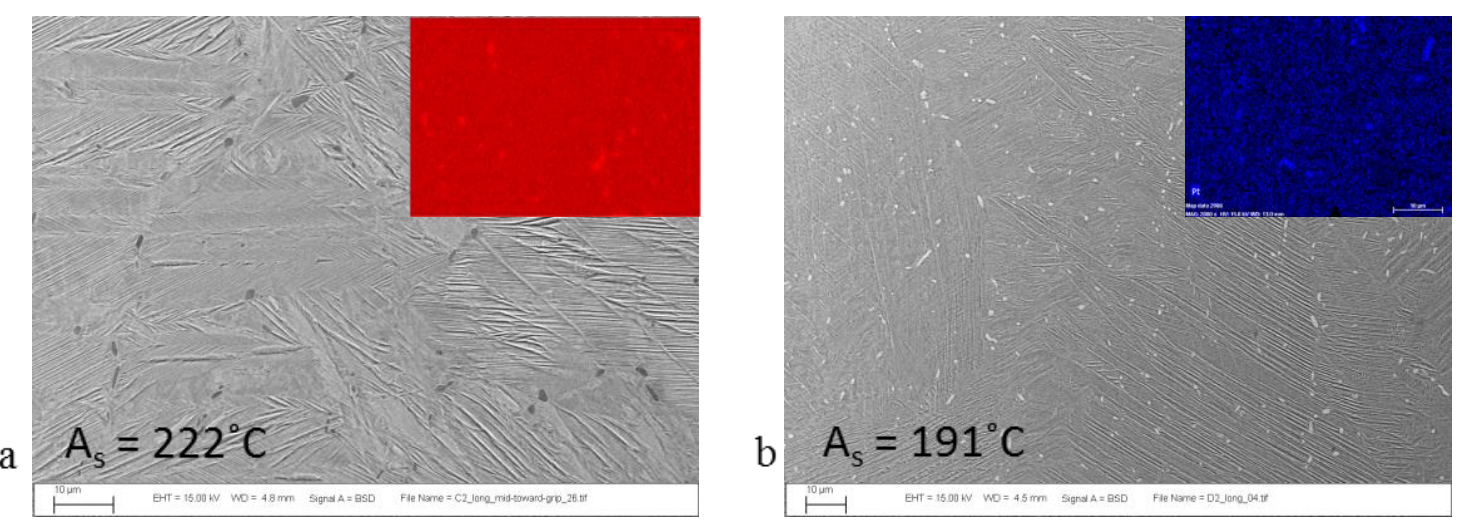

Fig. 2. Backscatter SEM photos of martensitic structure and EDS maps of $2^{\text {nd }}$ phases in nominal 16.5 at.\% $\mathrm{Pt}$ alloys with target composition 50.5 at.\% Ti. a) $\mathrm{The}^{\mathrm{Ti}}{ }_{2}(\mathrm{Ni}, \mathrm{Pt}) / \mathrm{Ti}_{4}(\mathrm{Ni}, \mathrm{Pt})_{2} \mathrm{O}_{\mathrm{x}}$ particles support a Ti-rich chemistry and b) (Ni,Pt)-rich precipitates indicate an off-target Ni-rich alloy.
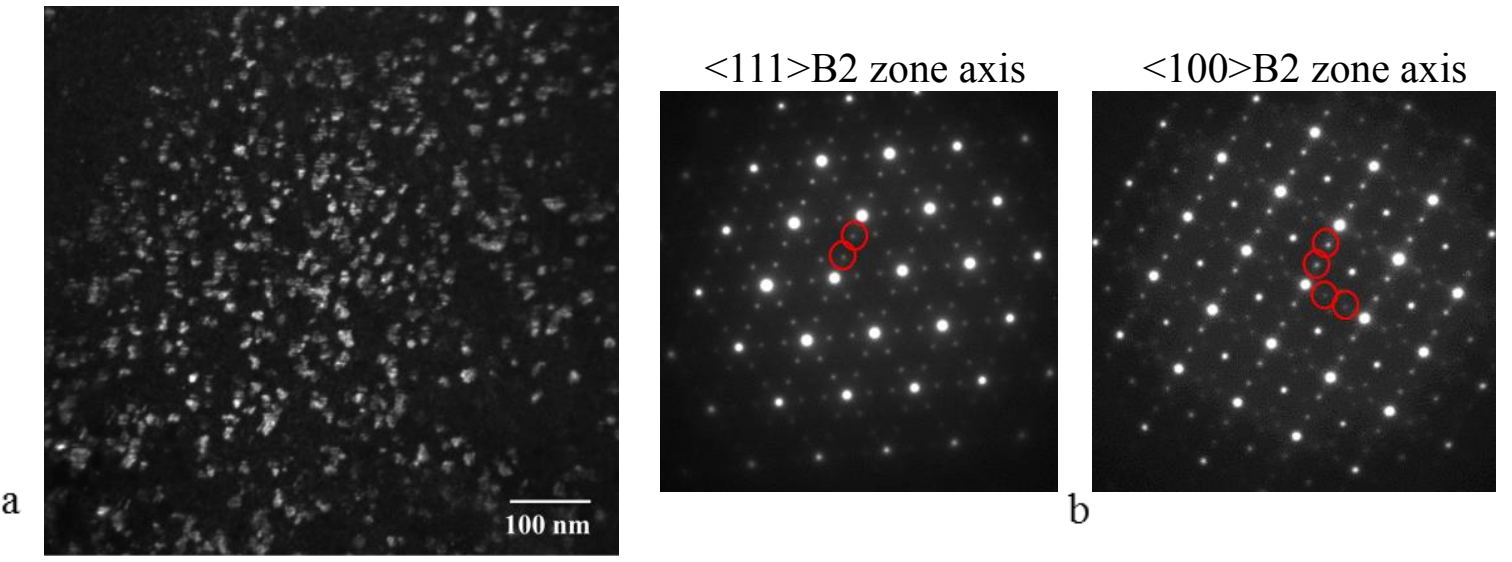

Fig. 3. a) Dark-field TEM photo of (Ni,Pt)-rich "P-phase" contained in sample shown in Fig. 2b above and b) corresponding diffraction patterns showing characteristic P-phase precipitate spots.[5] 